13

\title{
Эмиссионные свойства металлопористых катодов, модифицированных наноуглеродом
}

\author{
(C) Т.М. Крачковская ${ }^{1,2}$, Л.А. Мельников ${ }^{2}$ \\ ${ }^{1}$ Научно-производственное предприятие „Алмаз“, Саратов, Россия \\ ${ }^{2}$ Саратовский государственный технический университет \\ им. Гагарина Ю.А., Саратов, Россия \\ E-mail: elektron.t@bk.ru
}

Поступило в Редакцию 12 июля 2018 г.

Представлены результаты исследования эмиссионной способности, структуры и элементного состава поверхности импрегнированного катода с матрицей из мелкозернистого вольфрама с добавкой полиэдральных многослойных углеродных наноструктур фуллероидного типа (0.2-0.7 wt.\%), пропитанного алюминатом бария-кальция с добавкой сульфоаддукта нанокластеров углерода (0.1-0.2wt.\%). Испытания в диодных макетах показали, что такие катоды обеспечивают плотность тока $20 \mathrm{~A} / \mathrm{cm}^{2}$.

DOI: 10.21883/PJTF.2018.22.46916.17460

Проектирование современных электровакуумных приборов требует разработки источников электронов с повышенными значениями плотности тока. Для достижения высокой эмиссии в настоящее время исследуется применение в приборах СВЧ автокатодов [1] и скандиевых катодов [2], но их широкое распространение пока ограничено сроком их службы. Основным источником электронов в СВЧ-приборах остается металлопористый катод (МПК), для которого, однако, требуется повышение эмиссионных параметров.

Перспективными с точки зрения получения высоких эмиссионных характеристик представляются различные углеродные нанокластеры, интерес к которым сохраняется в течение последних десятилетий. Существует ряд работ, посвященных изучению подобных углеродных наноструктур в катодных системах. В частности, в литературе [3-5] показано положительное влияние добавки различных наноуглеродных кластеров на эмиссионные характеристики автоэмиссионных катодов. 
Авторы [3] указывают на модель возникновения эмиссии из углерода через электронное состояние с низким сродством, которое может быть локализовано на поверхности графитовых зерен или других форм углерода, таких как наноалмазы или фуллероиды (Астралены ${ }^{\circledR}$ ). Те же авторы приводят определенную в ходе эксперимента работу выхода подобных наноуглеродных материалов, равную приближенно 0.07-0.16 eV, что значительно ниже известной работы выхода из углерода, равной $4.5 \mathrm{eV}$. Кроме того, отмечается, что для материалов с такой маленькой работой выхода нагревание свыше $673 \mathrm{~K}$ может привести к тепловой эмиссии с плотностью тока пространственного заряда более $10 \mathrm{~A} / \mathrm{cm}^{2}$. Это свойство наноуглерода можно рассматривать как предпосылку применения его для модификации МПК, так как рабочие температуры термокатодов начинаются примерно с $953 \mathrm{~K}$.

В [6] уже сообщалось о применении наноуглерода для модификации МПК. Настоящая работа является продолжением данной публикации.

Матрица исследуемых катодов диаметром $2.8 \mathrm{~mm}$ состоит из мелкозернистой фракции вольфрама марки ВЧДК (фракция Б) с добавкой полиэдральных многослойных углеродных наноструктур фуллероидного типа - Астраленов ${ }^{\circledR}$ - и пропитана алюминатом бария-кальция с добавлением водного раствора сульфоаддукта нанокластеров углерода Углерона ${ }^{\circledR}$ - по технологии, описанной в [7].

Для исследования были изготовлены МПК с тремя типами обработки эмитирующей поверхности: вакуумный отжиг, вакуумный отжиг и глубокое ионное травление поверхности, вакуумный отжиг, глубокое ионное травление и покрытие композиционной пленкой с металлом платиновой группы.

Эмиссионные свойства катодов испытывались в диодах, откачанных до вакуума не менее $2 \cdot 10^{-7}$ Torr. Расстояние между катодом и анодом составляло $1 \mathrm{~mm}$. Перед исследованием катоды активировались при температуре $1473 \mathrm{~K}$ в течение $45 \mathrm{~min}$. Все температуры, указанные в исследовании, являются яркостными.

Сначала измерялись недокальные характеристики с токоотбором в $1 \mathrm{~A} / \mathrm{cm}^{2}$ в непрерывном режиме. По результатам измерений все варианты модифицированных катодов удовлетворяют критериям базовой технологии, принятой на предприятии, поэтому испытания были продолжены.

Для исследований на максимальную эмиссионную способность был выбран макет с модифицированным катодом, прошедшим все три этапа

Письма в ЖТФ, 2018, том 44, вып. 22 


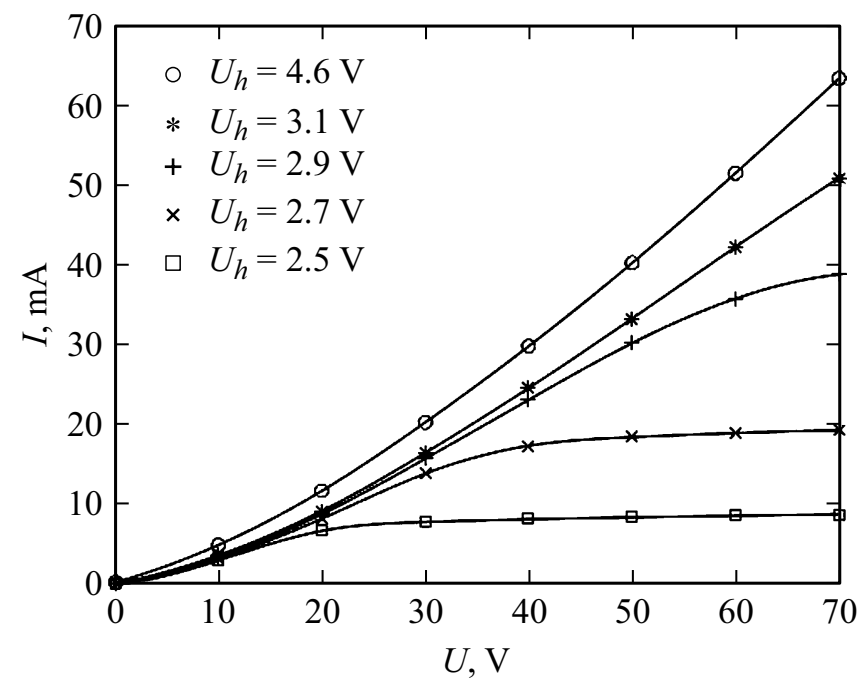

Рис. 1. Семейство ВАХ для МПК с Астраленами ${ }^{\circledR}$ и Углероном ${ }^{\circledR}$.

обработки эмиссионной поверхности. Были измерены вольт-амперные характеристики (BAX) в непрерывном режиме в диапазоне температур катода $1423-1023 \mathrm{~K}$, соответствующих напряжению накала катода $U_{h}$ от $4.6-2.5 \mathrm{~V}$ (рис. 1), а затем - недокальные характеристики при различном токоотборе (рис. 2). Во время всех замеров давление в обоих макетах составляло $8 \cdot 10^{-7}$ Torr.

Из рис. 2 видно, что температура, характеризующая переход работы катода из режима ограничения пространственным зарядом в режим с температурным ограничением, для плотности тока $20 \mathrm{~A} / \mathrm{cm}^{2}$ равна $1347 \mathrm{~K}$.

По данным ВАХ и пирометрирования был проведен расчет средней работы выхода электронов методом прямых Ричардсона: она составила $1.83 \pm 0.1 \mathrm{eV}$.

В настоящий момент данный макет проходит ускоренные испытания на долговечность, прогнозируемое значение которой составляет $100000 \mathrm{~h}$ при плотности тока $2 \mathrm{~A} / \mathrm{cm}^{2}$.

Письма в ЖТФ, 2018, том 44, вып. 22 


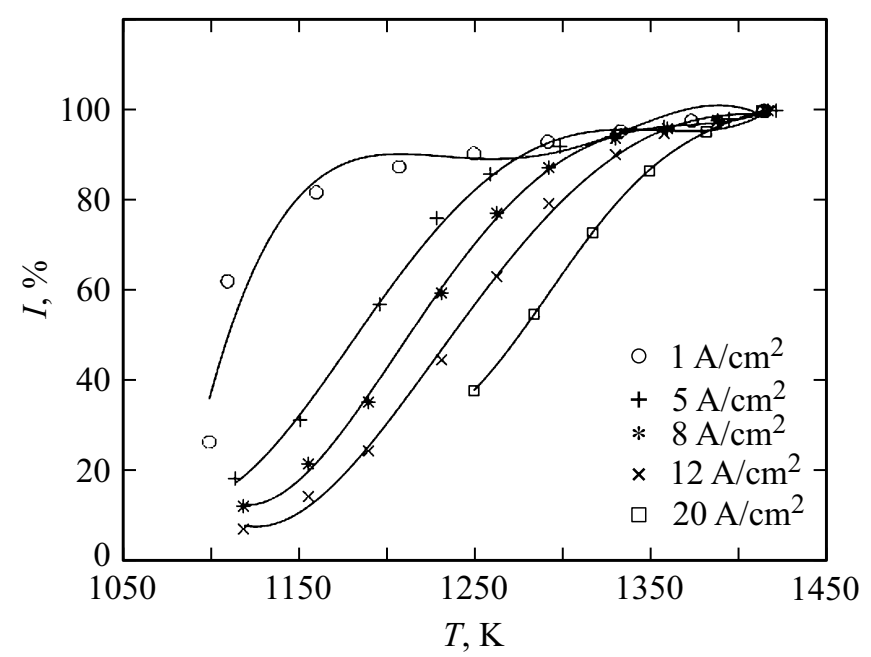

Рис. 2. Семейство недокальных характеристик МПК с Астраленами ${ }^{\circledR}$ и Углероном $^{\circledR}$.

Структура катода, прошедшего операцию вакуумного отжига, и катода с вакуумным отжигом и глубоким ионным травлением поверхности после измерения характеристик была изучена с помощью сканирующей электронной микроскопии. Поверхности указанных катодов представлены на рис. 3, $a$ и $b$ соответственно.

Из рисунков следует, что структура дисков низкопористая, плотная и не вполне равномерная. Кроме того, на эмиссионных поверхностях просматриваются частицы размером порядка $0.2-0.5 \mu \mathrm{m}$ на крупных зернах, чего не наблюдается у типовых катодов.

При изучении химического состава заданных поверхностей методом рентгеноспектрального анализа выявлено, что все найденные элементы на поверхности катода имеют типовую композицию $\mathrm{W}, \mathrm{Ba}, \mathrm{Al}, \mathrm{O}$, за исключением наличия Са. Это может свидетельствовать об измененном механизме протекания трехфазной реакции между вольфрамовым диском и активным веществом, так как обычно данный элемент на поверхности поработавшего типового катода присутствует. Перечисленные выше вещества обнаружены в пропорциях, примерно сопоставимых

Письма в ЖТФ, 2018, том 44, вып. 22 

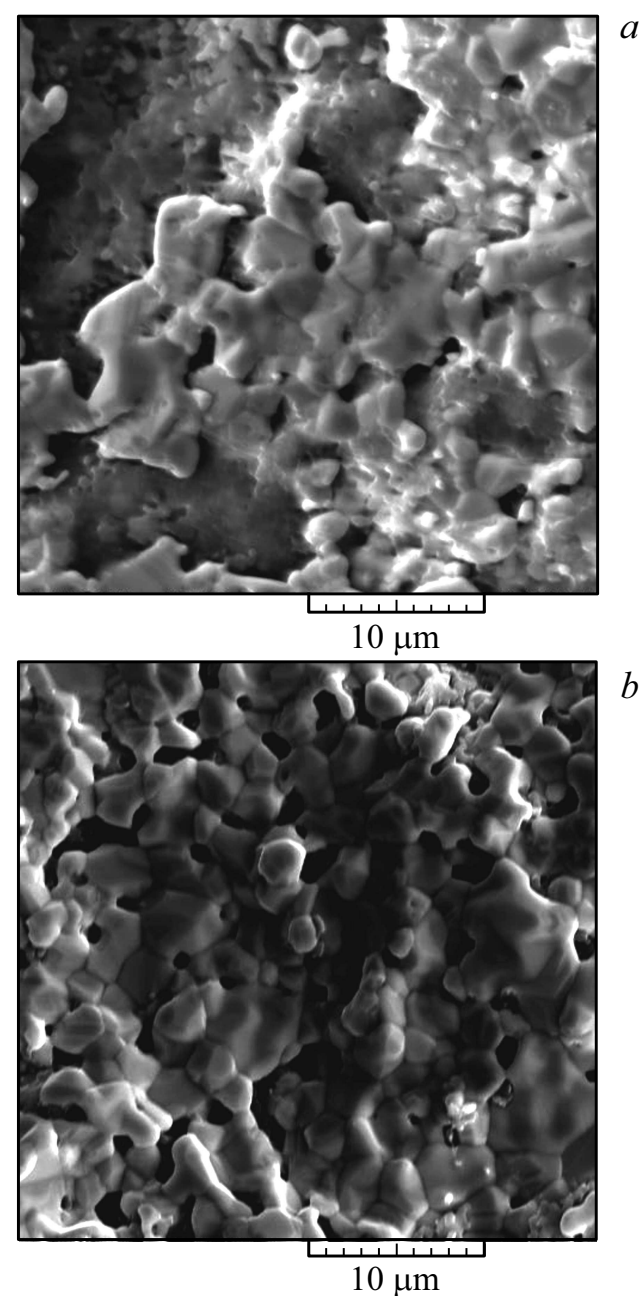

Рис. 3. Электронные изображения поверхности МПК после обработки поверхности вакуумным отжигом $(a)$ и вакуумным отжигом и глубоким ионным травлением $(b)$.

Письма в ЖТФ, 2018, том 44, вып. 22 
с таковыми для типовых катодов с указанными способами изготовления эмиссионной поверхности.

Объяснением полученных эмиссионных свойств исследуемых катодов может служить следующее. Во-первых, сульфоаддукт нанокластеров углерода (Углерон $\left.{ }^{\circledR}\right)$ является графеноподобной структурой, а именно неупорядоченным множеством графеновых листов, поэтому на него распространяются известные свойства таких структур. В частности, из литературы [8] известно, что графен абсорбирует молекулы газа из окружающей атмосферы, которые образуют примеси в слое графена. В нашем случае графеноподобные структуры, присутствующие в составе пропитки МПК, могут абсорбировать элементы активного вещества, что может привести к измененному механизму и скорости протекания трехфазных реакций образования активных элементов и кислорода. Косвенно это подтверждается результатами рентгеноструктурного анализа эмиссионных поверхностей катодов.

В той же работе [8] указывается на то, что с уменьшением глубины залегания примесных центров вероятность их ионизации возрастает. Это связано с тем, что при увеличении напряженности приложенного поля барьер уменьшается, поэтому уменьшается квазиклассическое действие, набираемое частицей при подбарьерном движении, и, следовательно, растет вероятность ионизации примесных центров. Кроме того, абсолютная величина постоянного тока увеличивается с повышением температуры. Также постоянный ток увеличивается с ростом концентрации примесей, а ионизация глубоких примесей начинается при довольно сильных полях, однако качественно рассмотренный эффект должен сохраняться.

В нашем случае для МПК максимальная ионизация будет создаваться вблизи эмитирующей поверхности и под действием электрического поля, приложенного относительно электродов в составе диода или прибора. Как следствие такого взаимодействия между примесями и графеноподобными структурами в активном веществе МПК вблизи эмитирующей поверхности будет формироваться дипольный монослой с их участием. В зависимости от ориентации графеноподобных структур в катодном диске они будут вносить разный вклад в формирование эмиссионных центров на поверхности и будут повышать эффективность пятнистого термокатода в случае перпендикулярного расположения их относительно приложенного электрического поля.

Письма в ЖТФ, 2018, том 44, вып. 22 
Во-вторых, углеродные наночастицы фуллероидного типа тороподобной формы (Астралены $\left.{ }^{\circledR}\right)$, присутствующие в металлической матрице исследуемых катодов, имеют соотношение радиуса тора с радиусом образующей его трубы, лежащее в диапазоне от $3: 1$ до 10:1 [9]. Этот факт обеспечивает возможность серьезного усиления внешнего поля вблизи их поверхности, как показано в работе [10], что существенно для достижения цели в области получения стабильных и высоких значений отбираемого тока эмиссии.

На основании полученных результатов можно судить о перспективности разработки металлопористых катодов с добавкой Углерона ${ }^{\circledR}$ и Астраленов ${ }^{\circledR}$ путем оптимизации параметров технологии их изготовления. Кроме того, учитывая свойства добавленных в МПК наноуглеродных структур, эффективность работы таких катодов можно дополнительно повысить с помощью эффекта Шоттки.

\section{Список литературы}

[1] Бушуев Н.А., Глухова О.Е., Григорьев Ю.А., Иванов Д.В., Колесникова А.С., Николаев А.А., Шалаев П.Д., Шестеркин В.И. // ЖТФ. 2016. Т. 86. В. 2. C. $134-139$.

[2] Сахаджи Г.В., Крачковская Т.М., Журавлев С.Д., Сторублев А.В. // Радиотехника. 2017. № 7. С. 60-69.

[3] Архипов А.В., Габдуллин П.Г., Гнучев Н.М., Давыдов С.Н., Крель С.И., Логинов Б.А. // Науч.-техн. ведомости СПбГПУ. Физ.-мат. науки. 2015. № 1(213). C. 77-92. DOI: 10.5862/JPM.213.8 [Arkhipov A.V., Gabdullin P.G., Gnuchev N.M., Davydov S.N., Krel S.I., Loginov B.A. // St. Petersburg Polytechnic University Journal: Physics and Mathematics. 2015. V. 1. P. 4755. DOI: 10.1016/j.spjpm.2015.03.011].

[4] Фурсей Г.Н., Поляков М.А., Кантонистов А.А., Яфясов А.М., Павлов Б.С., Божсевольнов В.Б. // ЖТФ. 2013. Т. 83. В. 6. С. 71-77.

[5] Бернацкий Д.П., Павлов В.Г. // ЖТФ. 2017. Т. 87. В. 11. С. 1729-1733. DOI: 10.21883/JTF.2017.11.45138.2260

[6] Крачковская Т.М., Сторублев А.В., Сахаджи Г.В., Емельянов А.С. Исследование характеристик металлопористого катода, модифицированного наноуглеродом // Сб. статей VII Всерос. конф. „Электроника и микроэлектроника СВЧ“. СПб.: СПбГЭТУ „ЛЭТИ““, 2018. С. 155-159.

[7] Крачковская T.М., Сахаджси Г.В., Сторублев А.В., Пономарев А.Н. Патент № 2658646 RU. МПК H01J9/04. Металлопористый катод и способ его изготовления. 2018.

2 Письма в ЖТФ, 2018, том 44, вып. 22 
[8] Носаева T.A. Влияние электрического и магнитного полей на электронные свойства графена. Канд. дис. Волгоград: Волгоград. гос. соц.-пед. ун-т, 2014. $110 \mathrm{c}$.

[9] Пономарев А.Н., Юдович М.Е. Патент № 2397950 RU. МПК C01B31/02 В82B1/00. Многослойные углеродные наночастицы фуллероидного типа тороидальной формы. 2010.

[10] Ponomarev A.N., Yudovitch M.E., Gruzdev M.V., Yudovitch V.M. // SITA-Journal. 2009. V. 11. N 3-4. P. 20-26. 